\title{
POLÍTICAS PÚBLICAS: EDUCAÇÃO E LINGUAGEM ${ }^{1}$
}

\author{
CLAUDIA CASTELLANOS PFEIFFER*
}

\begin{abstract}
RESUMO: Procuramos compreender, a partir do pressuposto de que os processos de escolarização e urbanização são indissociáveis, os modos por meio dos quais as políticas de ensino - enquanto políticas públicas - configuram possibilidades de inscrição do sujeito na história. Para tanto, investimos na análise da textualização que vai se construindo no batimento entre os modos de formulação das políticas públicas e das teorias que as sustentam.
\end{abstract}

Palavras-chave : discurso; política pública; ensino

RÉSUMÉ: Nous cherchons à comprendre, en supposant que le processus d'urbanisation et de scolarité sont inextricablement liées, les façons dont les politiques de l'enseignement - alors que politiques publiques configurent de possibilités d'inscription du sujet dans l'histoire. Pour ce faire, nous investissons dans l'analyse de la textualisation qui est construit dans l'articulation entre les modes d'élaboration des politiques publiques et les théories qui les soutiennent.

Mots-clés: discours; politiques publiques; enseignement

Dentro do que venho trabalhando no Laboratório de Estudos Urbanos da Unicamp, as políticas de ensino são uma ancoragem analítica para compreender o processo discursivo que configura o espaço do consenso para o sujeito que se inscreve em uma sociedade urbana pautada pela escrita. Do ponto de vista da área do Saber Urbano e Linguagem, instaurada pelo Labeurb, as relações sociais são relações de sentido. Nesse direção, ao tratar das políticas públicas, tratamos dos modos possíveis, ou não, de inscrição do sujeito na forma material da cidade, significada em sua urbanidade e em sua escrituralização.

Venho há um certo tempo mostrando que, na relação indissociável entre a escolarização e a urbanização, configuram-se sentidos para um sujeito urbano escolarizado inserido e tomado em/por uma sociedade que constrói seus espaços de significação tocados de uma só vez pelos sentidos da letra e da urbanização, em uma palavra: civilização (cf. Pfeiffer, 2002).

\footnotetext{
${ }^{1}$ Este artigo é fruto de minha pesquisa desenvolvida dentro projeto temático: A Produção do Consenso nas Políticas Públicas Urbanas: Entre o Administrativo e o Jurídico (CAeL) (processo Fapesp n 2004/ 07734-0) realizado no Labeurb/Nudecri-Unicamp sob a coordenação de Eni Orlandi.

*Doutora em Linguística - na área de análise de discurso - pela Unicamp, realiza suas pesquisas em torno dos processos de escolarização e de urbanização no Laboratório de Estudos Urbanos da Unicamp na carreira de pesquisador $(\mathrm{PqC})$. É docente credenciada no Programa de Pós-Graduação em Linguística do Instituto de Estudos da Linguagem da Unicamp, na área da História das Ideias Linguísticas. claupfe@yahoo.com
} 
É por isso que podemos pensar a escola² sob o efeito de um sentido republicano que a estabelece como o lugar de preparação e de evidência de qualidades dos homens que disputam, e já não mais herdam, lugares sociais. Mais do que isto, a escola é responsável por criar uma unidade cívica a partir de uma pluralidade cultural.

Dentro deste efeito mesmo de unidade e pluralidade, entra, na contemporaneidade, um outro: o da inclusão. O que temos analisado em diferentes pesquisas realizadas pela equipe do Laboratório de Estudos Urbanos mostra-nos que as políticas públicas têm se revestido de políticas de inclusão que demarcam limites e margens, produzindo a manutenção da desigualdade como operadora das relações sociais (cf. Orlandi, 2010). Particularmente, as políticas de ensino têm sido marcadas, entre outros fatores, por uma tentativa de um duplo movimento: o de levar em conta, a partir de uma perspectiva sócio-construtivista, o desenvolvimento individual do aluno (que tem um ritmo próprio na sua relação com o corpo social); e o de levar em conta, a partir de uma perspectiva antropológica, as estruturas sócio-culturais dos diversos grupos que integram uma mesma sociedade.

Neste duplo movimento percebemos o multiculturalismo e a ética individualizante (cf. Orlandi, 2001) como lugares de produção de consenso que, ao darem visibilidade aos indivíduos e a grupos de indivíduos, apagam os sujeitos. Em que sentido? No sentido de se trabalhar sempre com um referencial pré-construído que produz o lugar da diferença. Um referencial implícito sustentado por uma relação com a natureza (do indivíduo, do grupo), produzindo aí o lugar da diversidade. Isto é, a premissa parte de um consenso de indivíduo ideal (natural), para abrir espaço para os indivíduos “diversos", para então em um segundo momento alcançar novamente o ideal-indivíduo: heterogeneiza-se para homogeneizar. O multicultural não é multicultural em si, mas em relação a UM cultural ${ }^{3}$. Na busca de um ideal de completude, apaga-se o sujeito que pratica, na diferença, seus gestos de interpretação (cf. Orlandi, 1996).

É neste sentido que se faz importante buscar compreender os modos pelos quais as políticas educacionais têm sido construídas a partir do lugar do consenso do multiculturalismo e de uma ética individualizante das Instituições que fundam o Estado, que retira o sujeito da história e do social. Assim, o que venho buscando compreender é o modo pelo qual os sujeitos são interpelados pela administração jurídica do Estado no espaço das políticas de ensino assim constituídas.

Trago neste artigo uma parte de meu trajeto de reflexão ${ }^{4}$ que foi se configurando em torno de alguns pontos de ancoragem na relação entre as políticas públicas e o conhecimento.

\footnotetext{
${ }^{2}$ No caso do ensino da língua, a língua nacional é a língua cívica, civilizada, do Estado. Assim, no ensino da língua portuguesa (com seus instrumentos como a gramática, a literatura e mais atualmente a mídia em geral), vemos o trabalho do Estado (não se trata aqui do nível intencional) de homogeneizar sentidos, produzindo o consenso, apagando a diversidade. Produzindo na escrita o efeito máximo da unidade consensual. O sujeito brasileiro, eu diria o sujeito urbanizado, se torna visível pela escrita (por sua presença e por sua falta). A escola é tomada ainda como um dos principais lugares autorizados a construir a capacidade de sociabilidade. Se com a língua constrói-se a idéia de unidade linguística, com a história constrói-se a de unidade cronológica, com a geografia a de uma unidade nacional, a de um estado forte. A escola produz, assim, uma língua já pronta para seus alunos assim como uma cidade já pronta.

${ }^{3}$ Como tomamos discursivamente o sujeito como político, podemos ver aí uma pasteurização das relações de força e de sentidos neste novo processo de homogeneização.

${ }^{4}$ cf. Pfeiffer 2010a e 2010b.
} 
Nesse trajeto, alguns autores foram fundamentais e serão retomados detalhadamente. Os trabalhos de Newton Duarte, coordenador do grupo de pesquisa na UNESP de Araraquara sobre "Estudos Marxistas em Educação", especializado em psicologia da educação; os de Clarice Nunes, professora titular em história da educação, aposentada pela UFF; e os de Janete M. Lins de Azevedo, cientista social, docente da faculdade de educação da UFPE.

É por esta última autora que inicio essa leitura analítica. Janete de Azevedo (2004) destaca que "as políticas públicas, como qualquer ação humana, são definidas, implementadas, reformuladas ou desativadas com base na memória da sociedade ou do estado em que têm curso" (Azevedo, op.cit.: XIV). Prossegue a autora afirmando que as representações sociais predominantes fornecem os valores, normas e símbolos que estruturam as relações sociais e, como tal, fazem-se presentes no sistema de dominação, atribuindo significados à definição social da realidade que vai orientar os processos de decisão, formulação e implementação das políticas ( op . cit: XV). Aqui não podemos deixar de assinalar que parece haver um transporte para as relações sociais daquilo que é já efeito da produção do consenso. Ou seja, as "representações sociais" predominantes passam a significar as próprias relações sociais, há um efeito de colagem, fazendo das representações conteúdos.

Um pouco mais adiante, a autora irá precisar sua definição de política pública educacional: "constituem arquiteturas em que se fazem presentes, dentre outras dimensões, as soluções técnico-políticas escolhidas para operacionalizar internamente os princípios ditados pelo espaço global; o conjunto de valores que articulam as relações sociais; o nível de prioridade que se reserva à própria educação; as práticas de acomodação ou de resistência, forjadas nas instituições que as colocam em ação, seja nos sistemas de ensino ou nas próprias escolas" (op. cit.: XIX).

Por outro lado, a autora salienta que política pública também pode ser pensada em termos do Estado em ação. Como uma materialidade da intervenção do Estado. Estas políticas podem ser alteradas ou não de acordo com as gestões de cada governo, mas, sobretudo, podem ser interpretadas e projetadas ou ainda criticadas de modos diferentes de acordo com as teorias que as analisam. De nosso lado, diríamos que mais do que analisar as políticas públicas, essas diferentes abordagens demandam, projetam, e, portanto, fazem parte da constituição dos sentidos de Estado e de suas formas de intervenção. Trata-se, pois, de verificar, de um lado, consensos produzidos, pelo conhecimento científico, sobre qual é o papel do Estado e, portanto, qual é o papel de um dos seus principais instrumentos: as políticas públicas. Assim, a definição de uma política pública responde a uma definição teórica e a uma definição em termos de sua configuração que pode ou não ser coincidente com a teórica. Estamos lidando, pois, com um discurso sobre (científico) que interfere não somente nos ditos conteúdos de uma política pública, mas interfere, sobretudo, no papel consensual que a própria sociedade vê nessas políticas. Neste sentido, a divulgação científica é fundamental: algumas abordagens têm mais espaço na mídia, estabilizando o sentido. Por outro lado, mas não independente, é preciso analisar o que de fato se pratica nas políticas públicas, em nosso caso particular, nas educacionais. Tratarei do primeiro conjunto de análise para, depois, com o auxílio de Newton Duarte e de Clarice Nunes, buscar compreender um pouco sobre a segunda parte. 
Azevedo estabelecerá um longo e detalhado trajeto pelas diferentes abordagens que configuram as políticas públicas. Além de ater-me a uma breve síntese desse trajeto, também operarei com um drástico recorte para trazer o que me parece ser fundamental em termos de análise neste momento. Começaremos pela abordagem neoliberal, que tem sua base no liberalismo clássico do século XVII, quando o Estado ganha uma nova dimensão: a da igualdade, do alargamento dos direitos dos cidadãos. Esta é uma abordagem marcada por uma democracia utilitarista em que o Estado toma a forma da neutralidade, cabendo-lhe garantir os interesses públicos. Podemos, segundo Azevedo (op. cit.), tomar como máxima dessa corrente a frase usual "menos Estado e mais mercado". Vários são os argumentos que sustentariam essa máxima. Não adentrarei neles, apenas apontarei para um que tem uma relação mais direta e evidente com as políticas educacionais, qual seja: o de que a manutenção do bem-estar social tem um custo muito alto para o Estado que recai sobre apenas uma pequena parcela da sociedade. Friedman (apud Azevedo, op. cit.) chega a afirmar que a inflação e o desemprego são frutos da manutenção do bem-estar social. Neste sentido pareceria até contraditório vermos que essa corrente neoliberal defende uma política educacional pautada na idéia de que a ampliação da educação é um dos fatores mais importantes para a redução das desigualdades. A contradição se desfaz quando entendemos em que termos essa política se daria: o acesso ao nível básico de ensino seria da responsabilidade do Estado. Mas este nível deveria ter, da parte do Estado, uma contínua transferência ou divisão da responsabilidade administrativa com o setor privado. Este seria um meio de estimular a competição e a manutenção do padrão de qualidade na oferta dos serviços ("qualidade total") e de diminuir o inchaço da máquina pública e, consequentemente, os gastos públicos. Hayek (apud Azevedo, op.cit.) defende a mesma conduta por meio de argumentos de natureza diferentes: "a própria magnitude do poder exercido sobre a mente humana, que um sistema de educação altamente centralizado e dominado pelo governo coloca nas mãos das autoridades, deveria fazer-nos pelo menos hesitar antes de aceitá-lo. [...] Na verdade, quanto mais conscientes estivermos do poder que a educação pode exercer sobre a mente humana, mais convencidos devemos estar do perigo de entregar esse poder a uma única autoridade. [...] Hoje, como as tradições e instituições da educação universal estão firmemente implantadas e como a maioria dos problemas criados pela distância já foi resolvida pelo transporte moderno, não é mais necessário que a educação seja não só financiada pelo Estado como também ministrada por ele" (Hayek, 1983: 450-51, apud Azevedo, op.cit.). Quanto aos outros níveis, sobretudo os profissionalizante, a corrente neoliberal é taxativa em afirmar que o Estado não deve subsidiar nada. Desse modo, a política educacional como pública é colocada em suspenso pela corrente neoliberal, acusando o Estado de ser o responsável pelos problemas nos sistemas educacionais da atualidade.

Azevedo apresenta uma outra corrente que designa de "teoria liberal moderna da cidadania". Essa corrente apregoa que o bem-estar social e a igualdade constituem-se em pré-requisitos indispensáveis para o exercício pleno da individualidade e da liberdade e de que cabe ao Estado a responsabilidade pela garantia da promoção do bem comum. Titmuss e Marshall seriam os expoentes dessa corrente, fundamentada por elementos trazidos de Durkheim. Azevedo sustenta que, apesar de não ser classificada como tal, ela considera que a abordagem da social-democracia também deva estar nessa corrente. Isso porque o 
que de comum lhes dá unidade é considerarem as políticas sociais como instrumentos importantes no sentido de amenizar as desigualdades originadas no mercado. Vemos, portanto, que não se trata de uma crítica ao sistema, mas sim de uma adaptação (um saneamento!). Como em Análise de Discurso, a memória discursiva ${ }^{5}$ é constitutiva dos processos de significação, gostaria que, desde já, retivéssemos esse processo - de adaptação - que se mostrará no decorrer do trabalho como uma compreensão analítica forte a meu ver.

Os fundamentos de Durkheim retomados por essa corrente se baseiam, sobretudo, na sua compreensão de que a crescente especialização e a correlata diferenciação de funções estavam erodindo os valores comuns que haviam sido compartilhados no interior de uma sociedade tradicional. Para Durkheim, a solidariedade mecânica daria espaço para uma solidariedade orgânica, engendrando novas regras morais, baseadas na cooperação advinda da interdependência das novas funções (Durkheim, 1960, apud Azevedo, op.cit.). Para o autor, tal cooperação, entretanto, não é espontânea, cabendo ao Estado o papel de formular uma regulação mais vasta e complexa. Tratava-se, portanto, de uma ampliação de seu poder regulatório, sem suprimir a liberdade individual. Para Durkheim era preciso que se interferisse nos efeitos perversos produzidos pela divisão forçada do trabalho, expressos, segundo o autor, na coerção aberta e na alienação das tarefas. Durkheim propõe uma regulação jurídica precisa e abrangente das relações entre o capital e o trabalho e aponta para a necessidade de uma absoluta igualdade de condições exteriores para que todos tivessem a chance de competir pelo exercício das funções, ocupando-as segundo seus talentos e habilidades. Mais uma vez, gostaria que aqui também observássemos outra compreensão analítica que se desdobrará adiante. Essa memória discursiva que reverbera o tempo todo no sentido de individualizar a responsabilidade de ser e estar. Se o sistema é igual para todos, temos aí as habilidades e talentos inerentes ao indivíduo, para selecionar, destacar, dividir.

Nosso trajeto pelas análises de Azevedo (op. cit.) deixa-nos claro que as políticas educacionais se estruturam de forma geral enquanto instrumentos importantes no sentido de amenizar as desigualdades originadas no mercado. Essa amenização, justamente, aponta para uma direção de sentidos configurada pela evidência da necessidade de adaptação, de saneamento, de adequação. Este era o primeiro trajeto de uma leitura analítica que me propus a apresentar. $\mathrm{O}$ outro versa justamente sobre as tendências atuais em termos de pedagogias que circulam de maneira mais forte e fácil pelo espaço brasileiro, bem como sobre o processo histórico pelo qual o Brasil passa no que diz respeito às suas políticas educacionais que vão traçando uma configuração para o ensino.

Pensando na articulação das políticas com as teorias, já que as primeiras não se sustentam sem estas últimas, pelo menos sem uma pretensa sustentação teórica, podemos nos remeter, no que tange às práticas de ensino, a uma corrente predominante que pode ser designada de uma pedagogia do "aprender a aprender", conforme vemos com Newton Duarte (2001). O autor nos mostra que um dos pilares de sustentação dessa pedagogia é o

\footnotetext{
${ }^{5}$ Pêcheux (1999:52) afirma que a memória discursiva seria aquilo que "face a um texto que surge como acontecimento a ser lido, vem restabelecer os 'implícitos' (quer dizer, mais tecnicamente, os pré-construídos, elementos citados e relatados, discursos-transversos, etc.) de que sua leitura necessita: a condição do legível em relação ao próprio legível”.
} 
de que a educação deva preparar os indivíduos para acompanharem a sociedade em acelerados processos de mudança. Este posicionamento reclama para si uma distinção contundente em relação à educação tradicional que pressuporia uma sociedade estática, diferentemente da sociedade contemporânea em que uma nova educação é necessária para acompanhar a constante atualização frente aos conhecimentos provisórios, o que garantiria, sobretudo, empregabilidade.

Desse modo, o emprego e sua manutenção estariam atrelados a uma pedagogia que ensinasse ao indivíduo, sobretudo, adaptar-se. Aos educadores, como afirma Duarte, "caberia conhecer a realidade social não para fazer a crítica dessa realidade e construir uma educação comprometida com as lutas por uma transformação social radical, mas sim para saber melhor quais são as competências que a realidade social está exigindo dos indivíduos" (op.cit: 38).

Como vemos é 'adaptação' a palavra-chave que sustenta as pedagogias do "aprender a aprender". Já afirmamos que discursivamente é importante apontar para a demanda histórica por esta "capacidade de adaptação". Esta demanda nos indica uma prática consensual que estabiliza a sociedade capitalista tal como é. Desse modo, essa autonomia e liberdade do indivíduo só podem ser pensadas e estabilizadas, porque estamos em uma sociedade capitalista que atualiza sua memória por diferentes materialidades.

Justamente para avançar um pouco mais nesta memória discursiva que sustenta a estabilização das políticas públicas na evidência da adaptação e, portanto, na manutenção da desigualdade estruturante das sociedades capitalistas, percorro o trabalho de Clarice Nunes (2000) com quem vemos que o ensino no Brasil constitui-se por uma tensão fundante entre uma abordagem profissionalizante e uma humanista. A autora salienta o fato de que a LDB de 96, consagrará uma vocação humanista e cientificista ao ensino médio. Entretanto, como nos mostra Nunes, esta vocação não descarta a opção por um ensino profissionalizante para aqueles que assim "desejarem".

É justamente neste lugar da escolha e do desejo que quero investir analiticamente. Para tanto, recorro à análise histórica que Nunes (op.cit) faz sobre a educação brasileira, pensando-a como fundada por sentidos iluministas. A autora nos fará lembrar que no iluminismo há um forte embate entre Rousseau, Voltaire e Condorcet. E será este último filósofo que marcará as bases para a formulação do sistema de formação francês ${ }^{6}$. Este sistema ${ }^{7}$, conforme nos mostra Nunes, estruturado pelo pressuposto da igualdade de todos no acesso à instrução, estabelece ser o talento de cada um que assegura a possibilidade da diferenciação. No plano educacional elaborado por Condorcet, o secundário caberia àqueles que pudessem arcar com os custos de manter um jovem estudando sem trabalhar.

Fecha-se, a meu ver, uma rede discursiva que sustenta determinadas evidências na sociedade contemporânea. Para tanto, chamo à observação o inciso V do artigo 208 de Constituição Brasileira de 1988:

\footnotetext{
${ }^{6}$ Em 1792, Condorcet apresenta à Assembléia Nacional, como deputado e membro do Comitê de Instrução Pública, um projeto de decreto posteriormente aprovado que tratava da organização da instrução nacional.

${ }^{7}$ Em "Cinco memórias sobre a instrução pública" de Condorcet (2008) - publicadas em Paris, em quatro números do jornal Biblioteca do homem público no decorrer de 1791 - vemos que três são os princípios que devem orientar o sistema de instrução pública: o acesso universal, a gratuidade e a independência.
} 
Art. 208*. O dever do Estado com a educação será efetivado mediante garantia de: V- acesso aos níveis mais elevados do ensino, da pesquisa e da criação artísitca, segundo a capacidade de cada um.

Vejamos: há uma repetição que reverbera na memória sempre atualizada da educação a partir dos sentidos republicanos de igualdade. Essa memória aponta para uma concessão: todos têm acesso. Entretanto, a meritocracia se instala. É o talento de cada um - marca biológica - que garante o lugar social a ser ocupado. Assim a afirmação da divisão e de sua justificação resta legitimada ${ }^{8}$.

Se, de um lado, é preciso abordar as diferentes formas com que as políticas públicas se estruturam em termos de uma projeção que lhes é constitutiva, mas se dá como se fosse exterior as próprias políticas - isto é, o que circula sobre o escopo e forma como as políticas públicas devam ser e onde e como devam agir -, de outro lado, não se pode escapar ao imaginário estabilizado de que não importem as diferenças dessas abordagens, todas elas se inserem em uma sociedade democrática. Sentido opaco que nos demanda um contínuo investimento para que não sejamos pegos na evidência da diferença.

\section{REFERÊNCIAS BIBLIOGRÁFICAS}

CONDORCET, J-A-N. de Caritat, marquis de. (2008). Cinco memórias sobre a instrução pública. São Pulo: editora da Unesp.

DUARTE, N. (2001). As pedagogias do "aprender a aprender" e algumas ilusões da assim chamada sociedade do conhecimento. Revista Brasileira de Educação (ANPED), São Paulo, n. 18, pp. 35-40.

NUNES, C. (2000). O velho e o bom ensino secundário: dois momentos decisivos. Revista Brasileira de Educação (ANPED), São Paulo, n. 14, pp. 35-60.



ORLANDI, E. (2010). Discurso e políticas públicas urbanas: a fabricação do consenso. $1^{a}$. ed. Campinas: Editora RG.

. (2001). Tralhas e troços: o flagrante urbano. In: Eni Pulcinelli Orlandi. (Org.). Cidade atravessada. Campinas: Pontes, v. 1, p. 09-24.

. (1996). Interpretação: autoria, leitura e efeitos do trabalho do simbólico. Rio de Janeiro: Vozes.

PÊCHEUX, M. (1999). Papel da memória. In: Achard, P. et al. Papel da memória (Nunes, J.H., Trad. e Intr.). Campinas: Pontes.

ORLANDI, E.; GADET, F. (1981). La langue introuvable. Paris: Maspero.

PFEIFFER, C. (2010b). Linguística, Ensino e Legislação. In: Efeitos de Leitura: sujeitos e sentidos em movimento. $1^{\text {a }}$. ed. São Paulo: Editora Alphabeto, v.1, p. 13-28.

. (2010a). Políticas Públicas de ensino In: Discurso e políticas públicas urbanas: a fabricação do consenso. $1^{\text {a }}$. ed. Campinas: Editora RG, v.1, p. 85-99.

. (2002). Sentidos para Sujeito e Língua Nacionais. Língua e Instrumentos Lingüísticos. v.7, p.71 - 93.

\footnotetext{
${ }^{8}$ Não canso de lembrar Pêcheux (1981: 57) que afirma que a divisão antes visível passa a se dar, com a revolução burguesa, "em um confronto estratégico em um só mundo".
} 